\title{
Use of Complementary and Alternative Medicine among Young Patients with Breast Cancer
}

\author{
Friederike Hammersen $^{a}$ Telja Pursche ${ }^{b, c}$ Dorothea Fischer ${ }^{d}$ \\ Alexander Katalinic ${ }^{a, e}$ Annika Waldmann ${ }^{a, f}$

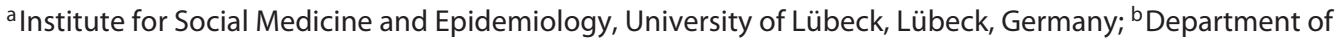 \\ Obstetrics and Gynecology, University Hospital of Schleswig-Holstein, Campus Lübeck, Lübeck, Germany;

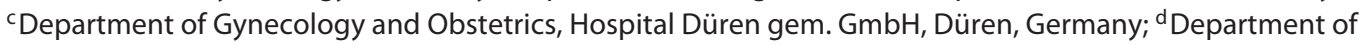 \\ Obstetrics and Gynecology, Hospital Ernst von Bergmann, Potsdam, Germany; ${ }^{\mathrm{e}}$ Institute for Cancer \\ Epidemiology e.V., University of Lübeck, Lübeck, Germany; ${ }^{f}$ Hamburg Cancer Registry, Hamburg, Germany
}

\section{Keywords \\ Complementary therapies · Breast neoplasm · Young patients · Rehabilitation program · Cohort studies}

\begin{abstract}
Background: Complementary and alternative medicine (CAM) has received increasing attention in Western countries and is especially common among breast cancer (BC) patients. So far, its effectiveness has not been well studied, which is in part due to the contextuality of CAM along with a lack of information of why patients use it. Objectives: Young $\mathrm{BC}$ patients constitute a special patient group regarding clinical characteristics, QOL, and their role in society. Since little is known about their CAM use, this study aimed at exploring it as well as their reasons for CAM use. Methods: Data on CAM and sociodemographics were collected via questionnaire in the context of a rehabilitation program for young mothers with BC. Initial BC diagnoses were between 2009 and 2014 (recruitment period 2012-2015). Clinical characteristics were derived from the patient files. Descriptive statistics were used to describe frequencies and statistically significant differences were tested. Results: Among the 827 patients, with an average age of 39.6 years, $62.5 \%$ had used CAM with regard to their cancer. CAM use was significantly higher in women with higher educational level, higher employment status, and statutory health insurance, re-
\end{abstract}

spectively. The average monthly expenses on CAM were EUR 50. Every 5th woman used CAM without her physician's knowledge. The types most often used were dietary supplements with vitamins or minerals. The most frequent reasons for CAM use were to strengthen the immune system, support conventional medicine, and combat side effects. Conclusions: CAM plays an important role for young $\mathrm{BC}$ patients with regard to prevalence and monthly expenses, and was used for a wide range of reasons. Certain subgroups with more frequent CAM use could be identified. Physicians should therefore proactively talk about CAM with their young $B C$ patients, so that patients do not need to rely on information sources on CAM outside the medical system.

(c) 2019 S. Karger AG, Basel

\section{Introduction}

Over the last decades, complementary and alternative medicine (CAM) has received increasing attention in Western countries [1-4]. CAM seems to be especially attractive to cancer patients, for whom it implies regaining a feeling of control over their situation. The decision to use CAM in addition to conventional treatment already counteracts one's felt passivity towards the disease and implicates a way of coping with the disease $[5,6]$. Furthermore, patients often perceive CAM as a holistic approach, 
including a more personal and individual way of medicine, as CAM practitioners can generally spend more time with each patient $[5,7]$.

Despite its popularity, research in the field of CAM is hampered by heterogeneous definitions and interpretations, including its practices and treatments $[1,7,8]$. A large project by the European Union reached the conclusion that the actual effectiveness of CAM is poorly understood so far [1]. This is also caused by the contextual nature of CAM - e.g., the importance of the belief in CAM, associated expectations, as well as the doctor-patient relationship - which complicates a quantification of CAM's effectiveness [1]. Bearing this in mind, it seems essential to first of all explore why patients use CAM. These reasons for use can then foster research about the effectiveness.

CAM is widespread, particularly among breast cancer (BC) patients $[6,9-12]$. As the mean age of $\mathrm{BC}$ diagnosis is over 60 years [13], studies on CAM, and BC in general, have mainly focused on older patients to date $[5,6,9-12$, 14]. Young BC patients differ in many aspects from older ones though. They typically hold a different role in society, which is characterized by occupation and family life. With a lot of lifetime still to come, their expectations with regard to long-term quality of life (QOL) also differ. Besides, they are often affected by more aggressive tumors in advanced stages with worse prognoses [15] and show an impaired QOL in terms of depressiveness, sleep problems, fatigue, and anxiety of recurrence when compared to older BC patients [16].

Taking young BC patients' special situation into account, treating clinicians have to weigh therapy benefits against potential harms, e.g., minimizing long-term toxicity and resulting impairments in QOL. Their situation leads to the question of whether young BC patients also differ with regard to CAM use. Since no data are available solely on young $\mathrm{BC}$ patients' CAM use, it is therefore necessary to identify the prevalence and corresponding reasons. Germany has the highest rate of CAM use in the EU [17], leading to a unique and an ideal study setting for this topic. The resulting research questions of this study were:

- What is the prevalence of overall CAM use in young BC patients?

- What characterizes young BC patients using CAM (e.g., sociodemographic and clinical factors)?

- Which types of CAM are used?

- What are the reasons for their CAM use?

\section{Materials and Methods}

\section{Study Design and Materials}

Data were obtained from a prospective cohort study conducted in the context of a rehabilitation program named "gemeinsam gesund werden" (meaning: get well together). In this mother- child rehabilitation program in Grömitz, North Germany, women with BC from all over Germany can participate. During their stay at the rehabilitation clinic, they are invited to participate in our cohort study. The study started 10 years ago and includes women who are affected by $\mathrm{BC}$ earlier than the average age of disease onset. Keeping their special situation in mind, the study aims at describing the patients' clinical characteristics, their oncological care, QOL, and impacts of the disease on their families. Research topics of the previous cohorts can be found on the website of the Institute for Social Medicine and Epidemiology.

\section{Eligibility}

The stationary rehabilitation program is open to mothers with a diagnosis of BC (ICD-10 C50) or ductal carcinoma in situ (ICD10 D05.1) after finishing their primary treatment and without signs of distant metastases. At least one child has to be under the age of 12 years. Hence, the participants represent a selected, younger cohort of women with BC. Out of the total study participants, we included women of cohort 3 (recruitment period 20122015) who met the inclusion criteria and filled in the questionnaire. Their initial diagnoses were made between 2009 and 2014. From an earlier cohort with a complete survey of clinical information we know that the response rate was quite high (cohort 2: $85 \%)$.

\section{Data Collection}

In each cohort, therapies and sociodemographics were surveyed, as well as cohort-specific topics (e.g., cohort 3: CAM, information seeking, and evaluation). The clinical staff administered the questionnaires at the beginning of the women's rehabilitation stay. Data from the patient files complemented these questionnaires. All participants gave written informed consent.

\section{Assessment of CAM}

Use of CAM was assessed with the question "During the past 12 months, have you used complementary/alternative medicine with regard to your cancer?" (yes/no). This question was checked for its reliability [18]. CAM users were then asked which types they had used regularly or now and then (multiple answers possible): (1) dietary supplements with vitamins and/or minerals; (2) antioxidants; (3) products to strengthen the immune system (e.g., vitamin E, ubiquinone, coenzyme Q10); (4) special cancer diet; (5) mistletoe therapy; (6) thymus preparations/therapy; (7) Bach flower remedies; (8) homeopathy; (9) naturopathy; (10) orthomolecular medicine; (11) traditional Chinese medicine; (12) yoga; (13) meditation; (14) hypnosis, and (15) acupuncture. For each CAM type, we created a dichotomous variable (i.e., used specific CAM type vs. not). Different CAM types were not classified into subordinate categories (e.g., herbal medicine). Eardley et al. [7], for example, point to conceptual inconsistencies regarding such categories in former studies, which prevented comparisons across studies. CAM users were asked whether their primary treating physician was informed about CAM ("No, my physician does not know about it;" "Yes, I informed my physician;" "Yes, I use CAM upon the advice of my physician") and for what reason(s) they had used CAM (multiple answers possible): (1) instead of conventional treatment for cancer (alternative); (2) additional support of conventional medicine/increase the chance of cure; (3) strengthen the immune system; (4) detoxification of the body; (5) avoidance or relief of side effects of therapy; (6) avoidance of menopausal symptoms; (7) improvement of QOL, and (8) would like to do something in addition. Another question related to monthly expenses resulting from CAM use (in euro). 
Table 1. CAM use by different basic patient characteristics

\begin{tabular}{|c|c|c|}
\hline & $\begin{array}{l}\text { CAM use } \\
(n=517 ; 62.5 \%)\end{array}$ & $\begin{array}{l}\text { No CAM use } \\
(n=310 ; 37.5 \%)\end{array}$ \\
\hline \multicolumn{3}{|l|}{ Age at diagnosis, years } \\
\hline Mean \pm SD & $39.8 \pm 5.4$ & $39.3 \pm 5.8$ \\
\hline Median [min-max] & $40.0[24-56]$ & $39.0[23-57]$ \\
\hline \multicolumn{3}{|l|}{ Age } \\
\hline$\leq 35$ years & $102(57.6)$ & $75(42.4)$ \\
\hline $36-\leq 40$ years & $180(63.8)$ & $102(36.2)$ \\
\hline $41-\leq 45$ years & $149(65.4)$ & $79(34.6)$ \\
\hline$\geq 46$ years & $80(64.0)$ & $45(36.0)$ \\
\hline$p$ value & 0.188 & \\
\hline \multicolumn{3}{|c|}{ Time period diagnosis - survey ${ }^{1, \#}$} \\
\hline 0 years & $307(62.1)$ & $187(37.9)$ \\
\hline 1 years & $193(63.9)$ & $109(36.1)$ \\
\hline 2 years & $10(66.7)$ & $5(33.3)$ \\
\hline 3 years & $0(0)$ & $0(0)$ \\
\hline 4 years & $0(0)$ & $0(0)$ \\
\hline 5 years & $1(100.0)$ & $0(0)$ \\
\hline \multicolumn{3}{|l|}{ Therapy } \\
\hline \multicolumn{3}{|l|}{ Surgery } \\
\hline $\mathrm{Yes}^{\#}$ & $514(62.9)$ & $303(37.1)$ \\
\hline No & $1(100.0)$ & $0(0)$ \\
\hline \multicolumn{3}{|l|}{ Radiation } \\
\hline Yes $^{\#}$ & $438(64.2)$ & $244(35.8)$ \\
\hline No & $79(57.2)$ & $59(42.8)$ \\
\hline \multicolumn{3}{|l|}{ Chemotherapy } \\
\hline Yes & $439(63.6)$ & $251(36.4)$ \\
\hline No & $69(58.0)$ & $50(42.0)$ \\
\hline$p$ value & 0.271 & \\
\hline \multicolumn{3}{|l|}{ Endocrine therapy } \\
\hline Yes & $367(63.8)$ & $208(36.2)$ \\
\hline No & $136(60.4)$ & $89(39.6)$ \\
\hline$p$ value & 0.390 & \\
\hline \multicolumn{3}{|c|}{ Axillary lymph node status } \\
\hline No & $287(60.7)$ & $186(39.3)$ \\
\hline N1 & $149(67.7)$ & $71(32.3)$ \\
\hline $\mathrm{N} 2$ & $45(62.5)$ & $27(37.5)$ \\
\hline N3 & $18(58.1)$ & $13(41.9)$ \\
\hline $\mathrm{Nx}$ & $13(56.5)$ & $10(43.5)$ \\
\hline$p$ value & 0.427 & \\
\hline \multicolumn{3}{|l|}{ Receptor status } \\
\hline ER positive & $365(63.7)$ & $208(36.3)$ \\
\hline$p$ value & 0.553 & \\
\hline PR positive & $322(62.6)$ & $192(37.4)$ \\
\hline$p$ value & 0.916 & \\
\hline Her2neu positive & $125(62.2)$ & $76(37.8)$ \\
\hline$p$ value & 0.083 & \\
\hline \multicolumn{3}{|l|}{ Tumor size } \\
\hline T0 & $43(57.3)$ & $32(42.7)$ \\
\hline $\mathrm{T} 1$ & $235(62.5)$ & $141(37.5)$ \\
\hline $\mathrm{T} 2$ & $179(63.5)$ & $103(36.5)$ \\
\hline T3 & $28(68.3)$ & $13(31.7)$ \\
\hline $\mathrm{T} 4$ & $2(50.0)$ & $2(50.0)$ \\
\hline $\mathrm{Tis} / \mathrm{Ta}$ & $16(55.2)$ & $13(44.8)$ \\
\hline $\mathrm{Tx}$ & $9(75.0)$ & $3(25.0)$ \\
\hline
\end{tabular}

\begin{tabular}{|c|c|c|}
\hline & $\begin{array}{l}\text { CAM use } \\
(n=517 ; 62.5 \%)\end{array}$ & $\begin{array}{l}\text { No CAM use } \\
(n=310 ; 37.5 \%)\end{array}$ \\
\hline \multicolumn{3}{|l|}{ Tumor subgroups ${ }^{2}$} \\
\hline Luminal A & $172(63.9)$ & $97(36.1)$ \\
\hline Luminal B1 & $92(71.3)$ & $37(28.7)$ \\
\hline Luminal B2 & $85(60.7)$ & $55(39.3)$ \\
\hline HER-2 like & $35(66.0)$ & $18(34.0)$ \\
\hline Basal like/triple negative & $90(59.6)$ & $61(40.4)$ \\
\hline Missing & $43(50.6)$ & $42(49.4)$ \\
\hline$p$ value & 0.058 & \\
\hline \multicolumn{3}{|l|}{ Statutory health insurance } \\
\hline Yes & $383(61.0)$ & $245(39.0)$ \\
\hline No & $125(69.8)$ & $54(30.2)$ \\
\hline$p$ value & $0.026^{*}$ & \\
\hline \multicolumn{3}{|l|}{ Educational level, school ${ }^{3}$} \\
\hline Low & $15(34.1)$ & $29(65.9)$ \\
\hline Middle & $172(54.8)$ & $142(45.2)$ \\
\hline High & $320(71.1)$ & $130(28.9)$ \\
\hline$p$ value & $<0.001^{* * *}$ & \\
\hline \multicolumn{3}{|l|}{ Employment (current or last) } \\
\hline Worker & $21(44.7)$ & $26(55.3)$ \\
\hline Employee & $390(62.5)$ & $234(37.5)$ \\
\hline Civil servant & $53(73.6)$ & $19(26.4)$ \\
\hline Freelancer & $36(78.3)$ & $10(21.7)$ \\
\hline Other & $10(55.6)$ & $8(44.4)$ \\
\hline$p$ value & $<0.001^{* * *}$ & \\
\hline \multicolumn{3}{|l|}{ Household income $e^{4}$} \\
\hline EUR $<1,500$ & $64(58.2)$ & $46(41.8)$ \\
\hline EUR $1,500-3,000$ & $210(59.2)$ & $145(40.8)$ \\
\hline EUR >3,000 & $216(68.4)$ & $100(31.6)$ \\
\hline$p$ value & 0.058 & \\
\hline \multicolumn{3}{|c|}{ Monthly expenses for CAM, EUR } \\
\hline Mean \pm SD & $86.0 \pm 109.58$ & - \\
\hline Median [min-max] & $50.0[0-1,000]$ & - \\
\hline \multicolumn{3}{|c|}{$\begin{array}{l}\text { Unless otherwise indicated values represent } n(\%) \text {. SD, standarc } \\
\text { deviation; } p \text { value obtained by } \chi^{2} \text { Pearson; }{ }^{*} p<0.05 ;{ }^{* * *} p<0.001 \\
{ }^{\#} \chi^{2} \text { test requirements not met: expected frequency was too small. } \\
1 \text { Time period between diagnosis and participation in the } \\
\text { survey. "0" means diagnosis and survey took place within } 1 \text { year } \\
{ }^{2} \text { According to Brouckaert et al. [19]. }{ }^{3} \text { Levels are derived from the } \\
\text { German school system. }{ }^{4} \text { Monthly net income of all householc } \\
\text { members after taxes and social contributions. }\end{array}$} \\
\hline
\end{tabular}

\section{Clinical and Sociodemographic Data}

Age at the time of diagnosis was reported as a continuous variable and grouped into 4 categories. Data collected from patient files included tumor characteristics such as hormone receptor status, HER2/neu status, tumor size, and axillary lymph node status. Classification of tumor subgroups was based on the 2011 St. Gallen surrogate definition [19], which uses tumor grade instead of Ki67. In case tumor grade was missing, we used the Ki67 if available. We chose this approach because information on Ki67 was missing in $68 \%$ of the Grömitz patients. This classification yielded 5 subgroups: luminal A; luminal B1; luminal B2; HER-2 like; and basal like/triple negative. Based on the German school system, educational level was grouped into 3 categories: "low" - 


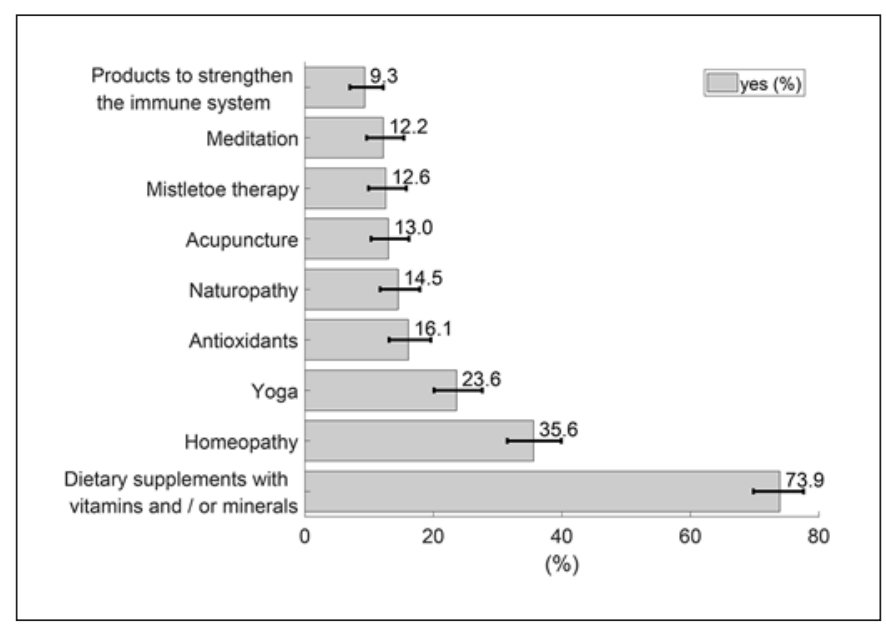

Fig. 1. Types of CAM used. Types are reported if they were used by at least $9 \%$ of CAM users. Multiple answers possible. Error bars indicate the confidence intervals. $n=517$.

until grade 9 or 10 (compulsory); "middle" - until grade 10; "high" - until grade 12 or 13. Income was queried in 3 categories $($ EUR $<1,500=$ low; EUR 1,500-3,000 = medium; EUR $>3,000=$ high) and refers to the monthly net income of all household members after taxes and social contributions. Participants were asked whether they had received sufficient information on the disease and treatment, respectively, and the former 4-point scale was grouped into 3 categories for this study. A dichotomous question referred to the wish to have received information on further treatment options.

\section{Statistical Analyses}

The results were described with absolute and relative frequencies, arithmetic means, medians, standard deviations (SD), and, where appropriate, with 95\% confidence intervals (CI), respectively.

We used $p$ values derived from a Pearson's $\chi^{2}$ test to examine statistically significant differences for a two-way table between CAM use and sociodemographic as well as clinical characteristics. Pearson's $\chi^{2}$ test results were not reported, however, if the expected frequency was $<5$ in more than $20 \%$ of the categories. Results were considered statistically significant when $p<0.05$. Results in Table 1 are presented as row percentages. It was assumed that if sociodemographic and clinical characteristics cause differences in CAM use, this will be seen in deviations from overall CAM use.

All statistical analyses were performed using SPSS version 22 (IBM).

\section{Results}

\section{Study Population: CAM Users versus Non-Users}

The 827 BC patients were on average 39.6 years old at diagnosis ( $\mathrm{SD} \pm 5.5$; range: $23-57$ years); $96 \%$ participated in the survey in the same year or the first year following their BC diagnosis. The majority of the women had used CAM with regard to their cancer $(n=517$; $62.5 \%$ ) (Table 1 ). The youngest age group ( $\leq 35$ years)

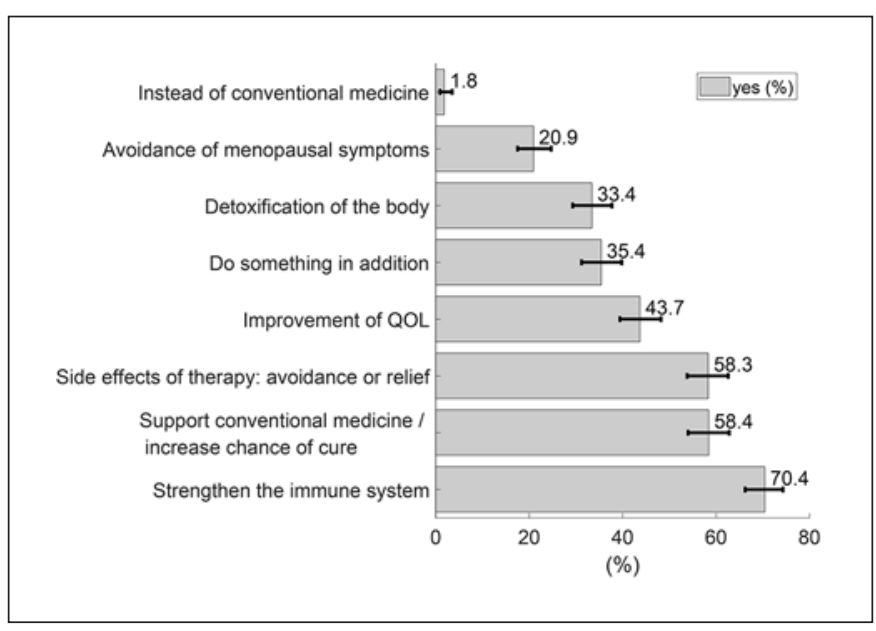

Fig. 2. Reasons for CAM use. Multiple answers possible. Error bars indicate the confidence intervals. QOL, quality of life. $n=503$.

had used slightly less CAM, but otherwise CAM use was similar among all age groups. We found a trend that CAM use was higher in women who had received radiotherapy, chemotherapy, and endocrine therapy, respectively. However, CAM use did not differ according to receptor or lymph node status. Women stratified according to tumor subgroups differed marginally in their use of CAM, with highest use among patients with BC luminal $\mathrm{B} 1$ and lowest use among basal-like/triple-negative $\mathrm{BC}$ patients. CAM use had little but stable increase with increasing tumor sizes. All differences and trends stated thus far were not significant. We found significant differences in CAM use in dependence of educational level, employment, and status of health insurance: CAM use strongly increased with the educational level. Similarly, civil servants and employees used CAM more often than workers. Women with statutory health insurance used CAM less often. Additionally, the highest income group reported the highest CAM use (difference not significant). On average, women spent EUR 50 (median) on CAM monthly - solely for reasons of cancer. Most physicians had knowledge about their patients using CAM: $63.3 \%$ had informed their physician and $15.8 \%$ were treated upon their physician's advice. Around every 5th woman used CAM without her physician's knowledge.

\section{CAM Types Used}

Dietary supplements with vitamins and/or minerals were the most common type of CAM and were used by more than 7 out of 10 women (Fig. 1). They were followed by homeopathy and yoga. Further types (e.g., antioxidants, acupuncture, or mistletoe therapy) were less common. 
Table 2. Evaluation of information and CAM use

\begin{tabular}{|c|c|c|c|c|}
\hline \multirow[t]{2}{*}{ Statement } & \multicolumn{2}{|l|}{ CAM use } & \multicolumn{2}{|c|}{ no CAM use } \\
\hline & $n(\%)$ & $95 \% \mathrm{CI}$ & $n(\%)$ & $95 \% \mathrm{CI}$ \\
\hline \multicolumn{5}{|c|}{ I received sufficient information regarding my disease } \\
\hline Rather disagree/disagree & $41(71.9)$ & $58.3-82.6$ & $16(28.1)$ & $17.4-41.8$ \\
\hline Somewhat agree & $247(63.8)$ & $58.8-68.6$ & $140(36.2)$ & $31.4-41.2$ \\
\hline Absolutely agree & $222(59.7)$ & $54.5-64.7$ & $150(40.3)$ & $35.3-45.5$ \\
\hline \multicolumn{5}{|c|}{$\begin{array}{l}\text { I received sufficient information on different treatment options to make my own decision } \\
\text { regarding treatment }\end{array}$} \\
\hline Rather disagree/disagree & $160(62.3)$ & $56.0-68.2$ & $97(37.7)$ & $31.9-44.0$ \\
\hline Somewhat agree & $188(67.4)$ & $61.5-72.8$ & $91(32.6)$ & $27.2-38.5$ \\
\hline Absolutely agree & $161(59.0)$ & $52.9-64.8$ & $112(41.0)$ & $35.2-47.1$ \\
\hline \multicolumn{5}{|c|}{ Would you have liked to be informed about further treatment options? } \\
\hline Yes & $212(68.4)$ & $62.9-73.5$ & $98(31.6)$ & $26.5-37.2$ \\
\hline No & $305(59.0)$ & $54.6-63.2$ & $212(41.0)$ & $36.8-45.4$ \\
\hline
\end{tabular}

\section{Reasons for CAM Use}

The most frequent reason for CAM use was to strengthen the immune system, which is consistent with dietary supplements being the CAM type most often used (Fig. 2). More than every 2nd woman used CAM to support conventional medicine or increase the chance of cure, as well as to either avoid or relieve side effects of cancer therapy. CAM use instead of conventional medicine showed very little relevance among our patients. To improve one's QOL, do something in addition, or detox the body were more important reasons for CAM use.

In a supplementary analysis, we checked for variations in dependence of sociodemographic and clinical characteristics. With increasing age, the avoidance/relief of side effects became more important. QOL, on the other hand, was an equally important reason among all age groups. The avoidance of menopausal symptoms was more important in older women. Socioeconomic variables like education and employment also revealed differences in associations with reasons for CAM. They were most pronounced in the lowest educational level, for whom strengthening the immune system and improvement of QOL, respectively, were most important. This trend was found in workers and women without chemotherapy, too, who used CAM most often to strengthen the immune system. CAM was more frequently used against side effects if women had received chemotherapy. Differences according to radiation or endocrine therapy were less distinct.

\section{Information and CAM Use}

CAM use differed in relation to how informed patients felt (Table 2). CAM use increased if patients felt that they had not received sufficient information regarding their disease. The amount of information received to make one's own decision regarding treatment, however, showed no distinct association with CAM use. Women who would have liked to have had more information on treatment options used CAM more often.

\section{Discussion}

While CAM has become increasingly popular in Western countries over the last decades [1-4] and is common in $B C$ patients [6, 9-12], its effectiveness outside the laboratory as well as its safety are still under-explored [1]. It is impossible to test its effects, though, without knowledge of the patients' patterns of use as well as the reasons for which they use CAM [1]. Although young BC patients exhibit differences in their role in society and tumor characteristics, studies rarely focus on this patient group. Therefore, little to nothing is known about their CAM use. In our cohort of young BC patients, CAM played an important role with regard to prevalence $(62.5 \%)$ and monthly expenses. This finding is in line with results of previous BC studies, where prevalences ranged between 40.1 and $63.0 \%$ among older cohorts $[6,9-11,14]$. The characteristics of those among our patients who are more likely to use CAM - namely with a higher education and employment, respectively - replicate what has been found among older cohorts [6, 9-12]. Furthermore, these studies showed that the "relatively" younger age also predicted a higher CAM use. Among the young BC patients, we noticed a small but not statistically significant increase in CAM use with growing tumor size as well as in women who had received chemotherapy, radiotherapy, and endocrine therapy, respectively. This indicates that CAM 
use is higher in more advanced stages, as has been concluded before $[10,11]$.

The previously found popularity of vitamins and minerals among BC patients $[5,10-12,14]$ corresponds to our results, as they were by far the most often used type of CAM among young patients. Besides substances like dietary supplements and homeopathy, physical and mental methods like yoga and meditation were also used. The usage of homeopathy was quite high in our cohort (35.6\%) when compared to earlier studies. To understand this finding, it is essential to mention Germany's special position with regard to CAM: its general population has the highest CAM use within the European Union, and homeopathy use is more common than in other countries. This is probably due to basic conditions, as some CAM therapies are covered by specific statutory health insurances, and because homeopathy originated in Germany [17].

When it comes to reasons for CAM use, our participants stated a wide range of reasons. Together with the types of CAM used, we see that CAM is not only used curatively for medical conditions, but also for preventive reasons, relaxation, and to gain a feeling of "doing something". In general, CAM use has been found to be more common in patients with ambiguous health states and this could reflect the patients' reaction to the lack of understanding as to why it is they who fell ill [17]. Using CAM can thus function as a way of coping with a disease $[5,6,17]$, which is mirrored in statements of previous studies, where BC patients as well as their doctors mentioned that using CAM gave the patients a feeling of "fighting" the cancer and "gain[ing] a sense of control over [their] health" [6]. This is in line with our cohort expressing the motive to "do something" besides conventional treatment (expressed by 35.4\%). Young BC patients especially have to fight the dissonance of why they are affected by the disease although they are not part of the typical risk group. CAM instead of conventional medicine, on the other hand, was very rare in our study, as has also been shown in an analysis of the US National Cancer Database [20].

We found that - while improvement of QOL was equally important to all age groups - the handling of side effects gained importance with increasing age. One reason could be that even for younger patients, it becomes more difficult to bear side effects when becoming older. This could function as an indicator for health providers, when knowing that side effects and more advanced stages, respectively, and CAM use are likely to go along with each other. The variations in reasons according to socioeconomic variables fit in with the mentioned finding that CAM use in general also differs with regard to socioeconomic factors. However, we found no explanation for the association with specifically strengthening the immune system. It can be speculated that this finding is associated with a lower knowledge of common CAM indications in women with lower educational level. To the best of our knowledge, no other study has examined reasons in dependence of other factors as detailed to date and further research is needed to clarify this finding. It seems plausible that CAM gained importance with regard to side effects when women had received chemotherapy before. Possibly, these women also received advice on medication for their immune system along with chemotherapy, and thus CAM was not used for this matter.

Moreover, our results indicate that $\mathrm{BC}$ patients who are feeling ill-informed by their physician are more likely to use CAM, and also when they had desired to be informed about further treatment options. This is understandable when considering that only $16 \%$ of CAM users were treated upon their physician's advice with CAM, thus leaving room for many women with whom CAM probably had not been discussed. Previous research showed that dissatisfaction with conventional medicine often triggers patients to turn to CAM, where they experience a better and more personal relationship with their CAM practitioner, causing a feeling of being better looked after $[1,5,7]$. When patients are questioned about used information sources on CAM, they locate these rather outside the health care system and state that family, friends, as well as the media were their primary information sources $[9,11$, 12]. At the same time, patients stated that they would have liked to be informed about CAM within their specialist system [11], which clearly points towards a gap. A recent study found that the internet was not only an important information source, but in part the only possibility to get information related to this topic [21]. As the internet also contains many unchecked or even invalid information, this disturbing result should not be neglected.

\section{Methodological Considerations}

A major strength of the study was the large sample size with a total of 827 young BC patients from all over Germany. The concentration on young BC patients with children enabled us to examine effects which might easily be overlooked in an age-mixed cohort. Participants were asked about their CAM use in the previous 12 months, which is an advantage according to Eardley et al. [7], as many studies on CAM use exceed this time frame and thus promote a recall bias. On the other hand, we did not ask about previous patterns of CAM use and therefore do not know whether CAM use is a newly adopted behavior after the cancer diagnosis or a continued one. Due to a separation of research team and clinical staff, we were not able to calculate a response rate for cohort 3. Based on cohort 2 (recruitment between 2010 and 2011), however, we can assume a good response rate. The generalizability of our study findings is limited to patients with children up to the age of 12 years, and our cohort had a rather high 
educational level accompanied by a middle or high income. In Germany it is known that a higher socioeconomic status goes along with a higher utilization of early screening measures on $\mathrm{BC}$ [22] and hence more diagnoses, which could, in part, explain why patients with higher socioeconomic status are overrepresented in our cohort. Another reason to consider is that a higher socioeconomic status probably facilitates the application for a rehabilitation program (e.g., knowledge on the possibility itself, information seeking, as well financial situation). Tautz et al. [11] found a higher CAM use in patients with advanced BC stages (e.g., with recurrences or metastases). Taking this as well as our eligibility criteria into account, the overall population of young $\mathrm{BC}$ patients (consisting of patients with and without distant metastasis) can be expected to have an even higher rate of CAM use.

\section{Conclusion}

Our findings confirm results obtained in studies among older cohorts, namely that CAM proves to be a relevant issue also among young $\mathrm{BC}$ patients. Because CAM is extremely contextual, it is essential to know why patients turn to it. With our study results on the diverse reasons for CAM use, further research, e.g., on its effectiveness, can be promoted. Nevertheless, physicians and oncologists should already now proactively talk about CAM with their patients and routinely bring up information on it, so that patients do not need to rely on other sources such as the worldwide web. This recommendation has recently been stressed in the updated German guideline on $\mathrm{BC}$ [23]. As few physicians are experts in the field of CAM, training for them on how to conduct a conversation about CAM with their patients would be a helpful tool. Since an additional qualification in the field of CAM for all physicians is not feasible, cooperation with experts would be a first step in addition to the conversational training. Physicians should also be aware that young $\mathrm{BC}$ patients with a higher education, employment status, as well as more advanced stages, respectively, tend to use CAM more frequently.

\section{Acknowledgments}

We thank "Klinik Ostseedeich" in Grömitz and especially the patients for their cooperation.

\section{Statement of Ethics}

The study was approved by the ethics committee of the University of Lübeck (Ref. No. 10-096; amendment 2; 01.07.2012). It was conducted in accordance with the Declaration of Helsinki. All participants gave written informed consent to participate in the study.

\section{Disclosure Statement}

The authors have no conflicts of interest to declare.

\section{Funding Sources}

This study did not receive funding from external bodies. It was financed solely by the Department of Obstetrics and Gynecology, University Hospital of Schleswig-Holstein, and the Institute for Social Medicine and Epidemiology, University of Lübeck.

\section{Author Contributions}

D.F., A.W., and F.H. developed the research question. D.F. and A.W. made substantial contributions to the conception and design of the study. F.H., A.W., and T.P. made substantial contributions to data interpretation. All authors reviewed, edited, and approved the final paper.

\section{References}

1 Fischer FH, Lewith G, Witt CM, Linde K, von Ammon K, Cardini F, et al. High prevalence but limited evidence in complementary and alternative medicine: guidelines for future research. BMC Complement Altern Med. 2014 Feb;14(1):46.

2 Horneber M, Bueschel G, Dennert G, Less D, Ritter E, Zwahlen M. How many cancer patients use complementary and alternative medicine: a systematic review and metaanalysis. Integr Cancer Ther. 2012 Sep;11(3):187203.

3 Robert Koch-Institut. Statistisches Bundesa$\mathrm{mt}$ : Inanspruchnahme alternativer Methoden in der Medizin. Gesundheitsberichterstattung des Bundes. Volume 9. Berlin: Robert Koch-Institut; 2002.
4 World Health Organization. WHO global atlas of traditional, complementary and alternative medicine. Map Volume. Kobe, World Health Organization Centre for Health Development, 2005.

5 Lengacher CA, Bennett MP, Kip KE, Gonzalez L, Jacobsen P, Cox CE. Relief of symptoms, side effects, and psychological distress through use of complementary and alternative medicine in women with breast cancer. Oncol Nurs Forum. 2006 Jan;33(1):97-104.

6 Fox P, Butler M, Coughlan B, Murray M, Boland $\mathrm{N}$, Hanan T, et al. Using a mixed methods research design to investigate complementary alternative medicine (CAM) use among women with breast cancer in Ireland. Eur J Oncol Nurs. 2013 Aug;17(4):490-7.
7 Eardley S, Bishop FL, Prescott P, Cardini F, Brinkhaus B, Santos-Rey K, et al. A systematic literature review of complementary and alternative medicine prevalence in EU. Forsch Komplementmed. 2012;19 Suppl 2:18-28.

8 Falkenberg T, Lewith G, Roberti di Sarsina P, von Ammon K, Santos-Rey K, Hök J, et al. Towards a pan-European definition of complementary and alternative medicine-a realistic ambition? Forsch Komplement Med. 2012;19(s2 Suppl 2):6-8.

9 Molassiotis A, Scott JA, Kearney N, Pud D, Magri M, Selvekerova S, et al. Complementary and alternative medicine use in breast cancer patients in Europe. Support Care Cancer. 2006 Mar;14(3):260-7. 
10 Pedersen CG, Christensen S, Jensen AB, Zachariae R. Prevalence, socio-demographic and clinical predictors of post-diagnostic utilisation of different types of complementary and alternative medicine (CAM) in a nationwide cohort of Danish women treated for primary breast cancer. Eur J Cancer. 2009 Dec; 45(18):3172-81.

11 Tautz E, Momm F, Hasenburg A, Guethlin C. Use of complementary and alternative medicine in breast cancer patients and their experiences: a cross-sectional study. Eur J Cancer. 2012 Nov;48(17):3133-9.

12 Wanchai A, Armer JM, Stewart BR. Complementary and alternative medicine use among women with breast cancer: a systematic review. Clin J Oncol Nurs. 2010 Aug;14(4):E4555.

13 Robert Koch-Institut, die Gesellschaft der epidemiologischen Krebsregister in Deutschland (e.V.). Krebs in Deutschland für 2013/2014. 11. Ausgabe. Berlin, Robert KochInstitut, 2017.

14 Neuhouser ML, Smith AW, George SM, Gibson JT, Baumgartner KB, Baumgartner R, et al. Use of complementary and alternative medicine and breast cancer survival in the Health, Eating, Activity, and Lifestyle Study. Breast Cancer Res Treat. 2016 Dec;160(3): 539-46.
15 Banz-Jansen C, Heinrichs A, Hedderich M, Waldmann A, Dittmer C, Wedel B, et al. Characteristics and therapy of premenopausal patients with early-onset breast cancer in Germany. Arch Gynecol Obstet. 2012 Aug; 286(2):489-93.

16 Champion VL, Wagner LI, Monahan PO, Daggy J, Smith L, Cohee A, et al. Comparison of younger and older breast cancer survivors and age-matched controls on specific and overall quality of life domains. Cancer. 2014 Aug;120(15):2237-46.

17 Kemppainen LM, Kemppainen TT, Reippainen JA, Salmenniemi ST, Vuolanto PH. Use of complementary and alternative medicine in Europe: health-related and sociodemographic determinants. Scand J Public Health. 2018 Jun;46(4):448-55.

18 Waldmann A, Dreckschmidt J, Pritzkuleit R, Katalinic A. Test-Retest Reliabilität des OVIS-Fragebogens-ein Instrument zur Evaluation der onkologischen Versorgung aus Patientensicht. Gesundheitswesen. 2010 Oct;72(10):707-13. German.
19 Brouckaert O, Laenen A, Vanderhaegen J, Wildiers H, Leunen K, Amant F, et al. Applying the 2011 St Gallen panel of prognostic markers on a large single hospital cohort of consecutively treated primary operable breast cancers. Ann Oncol. 2012 Oct;23(10):257884.

20 Johnson SB, Park HS, Gross CP, Yu JB. Use of Alternative Medicine for Cancer and Its Impact on Survival. J Natl Cancer Inst. 2018 Jan; 110(1): 110 .

21 Holmes MM, Bishop FL, Calman L. "I just googled and read everything": exploring breast cancer survivors' use of the internet to find information on complementary medicine. Complement Ther Med. 2017 Aug;33: 78-84.

22 Starker A, Sass AC. [Participation in cancer screening in Germany: results of the German Health Interview and Examination Survey for Adults (DEGS1)]. Bundesgesundheitsblatt Gesundheitsforschung Gesundheitsschutz. 2013;56(5-6):858-67. German.

23 Leitlinienprogramm Onkologie. Deutsche Krebsgesellschaft DK, AWMF. Leitlinienprogramm Onkologie. S3-Leitlinie Früherkennung, Diagnose, Therapie und Nachsorge des Mammakarzinoms, Version 4.0, AWMF Registernummer: 032-045OL. 2017. Available from: http://www.leitlinienprogramm-onkologie.de/leitlinien/mammakarzinom/. 